See discussions, stats, and author profiles for this publication at: https://www.researchgate.net/publication/337799635

\title{
The Role of Individual Risk Attitudes on Old Wine Valuations
}

Article · December 2019

DOI: $10.1017 /$ jwe.2019.43

\section{CITATIONS}

0

2 authors:

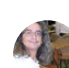

Nikolaos Georgantzis

Burgundy School of Business

129 PUBLICATIONS 856 CITATIONS

SEE PROFILE

Some of the authors of this publication are also working on these related projects:

Project Industrial Organization View project

price dispersion in search markets View project
Jean-Christian Tisserand

Burgundy School of Business

10 PUBLICATIONS 25 CITATIONS

SEE PROFILE 


\title{
The role of individual risk attitudes on old wine valuations ${ }^{1}$
}

\section{Nikolaos Georgantzis ${ }^{2}$ and Jean-Christian Tisserand ${ }^{3}$}

\begin{abstract}
In this paper, we report results from an experiment designed to address the effect of risk attitudes on valuations of aged wines. We find that higher risk-taking in the economic domain is associated with a significantly higher willingness to pay for an old wine. Given the increasing interest of consumers and investors in old wines, our results are applicable to the pricing of old wines and to the use of auctions as an efficient WTP elicitation mechanism.
\end{abstract}

JEL classifications: L66, D44, C91.

Keywords: Wine economics; Risk attitudes; Auctions.

\footnotetext{
${ }^{1}$ We would like to thank the anonymous referee and those present at the presentation of this article to AAWE 2019 for their valuable comments.

${ }^{2}$ CEREN, EA 7477, School of Wine \& Spirits Business, 29 rue Sambin, 21000 Dijon, France LEE and Department of Economics, Universitat Jaume I, Castellòn, Spain, E-mail : nikos.georgantzis@bsb-education.com.

${ }^{3}$ Corresponding author. CEREN, EA 7477, School of Wine \& Spirits Business, 29 Rue Sambin, 21000 Dijon, France - Swiss Distance Learning University (UniDistance), Überlandstrasse 12, Postfach 265 CH-3900 Brigue, E-mail: jean-christian.tisserand@bsb-education.com.
} 


\section{Introduction}

Properly stored wine ages to a superior product up to a moment at which it rapidly deteriorates. In specific cases in which the aging process has not been controlled by the seller, the effect of time on wine quality becomes even more uncertain. A trendy cava-wine bar in Dijon, France ${ }^{4}$, has recently decided to resell old wine which it purchased from private sellers. Recognizing the uncertainty entailed in the lack of control over the product's life until it reached the shop's shelves, the owner fixed a unique price (25€) for all the wines, informing their customers that the quality of aging process could not be guaranteed. In the concrete case of that specific bar, after all bottles were sold, the ex post share of "bad" wine was $10 \%$. Wine expert estimations vary, but most of them expect that less than $10 \%$ of wines improve after 1 year and no more than $1 \%$ of wines keep improving after 10 years. While aging cheap wines will most likely result in a deterioration of the wine's quality, some types of wines might improve their quality over decades if properly stored. Wines that are made to be aged are nevertheless rather the exception than the rule and most of wines quickly reach their optimal age of consumption. Of course, several tips can be used in order to identify a wine that did not age well. For example, if the space between the cork and the wine is too long, this could be a sign that the wine has oxidized or evaporated through the cork. Even though a bottle of aged wine doesn't show any sign of bad quality, the taste of the wine that is inside is not guaranteed, except maybe for high skilled connoisseurs who have a very good knowledge of the product. That said, even if knowledge of the product certainly makes it possible to minimize the risk, there is no such thing as zero risk in the case of aged wines and there is still a higher or lower probability that the content of the bottle has turned sour.

${ }^{4}$ Look for details at: $\underline{\text { http://www.pharmacy.vin/en/. }}$ 
The aforementioned value formation process and the decisions involved in the resale of old wine resemble those of a risky financial asset which is gradually increasing its value until the bubble explodes causing losses to the asset's owners (Noparumpa et al., 2015) . $^{5}$ Given that financial assets are not as tangible as wine, there are few guarantees about the optimal moment at which the owner should sell. The link between old wine valuations and individual buyers' risk attitudes becomes then very likely to exist. Riskier buyers should be willing to pay more than risk-averse ones for old wine and the effect should be stronger for older wines. The relevance of addressing this hypothesis is twofold: first, the optimal prices of old wine may depend on the buyers' risk attitudes; second, we can assess the external validity of in-lab risk elicitation instruments using a tangible asset, whose value uncertainty originates in an uncontrolled process, naturally occurring out of the lab.

Risk is subjective in nature and its perception involves many factors including psychological, social and cultural factors. The study of risk perception mostly implies examining the opinions that individuals express when they have to evaluate more or less risky activities in various ways. A large number of studies have focused on the perception of risk (mainly monetary) across different categories of individuals. Different individuals will react in various ways to comparable uncertain circumstances. Psychologists and economists have conducted numerous experiments in order to identify risk-taking and risk averse people's profiles (see for example Holt and Laury, 2002 and reviews by Andersen et al. 2006, Charness et al. 2013 and Attanasi et al. 2018). These experiments have allowed us to learn more about the perception of risk by different types of individuals. For example, we know that women on average, have a significantly higher risk perception than men (García Gallego et al., 2012). With regard to education/training, the majority of studies agree that more educated people are also the least risk-averse. On the other hand, age, which is also one of the variables that have attracted particular interest, does not seem to be correlated with a certain type of risk preference.

\footnotetext{
${ }^{5}$ This is especially likely to happen when the consumption of the wine peters out (Jovanovic, 2007).
}

Commenté [JT1]: highly recommended: AAWE Working Paper No. 32 - Economics Bubbles in Prices of Exhaustible Resources Boyan Jovanovic 
Despite the large number of studies conducted on the subject for more than 40 years now, the literature remains silent about the link between individual risk attitudes and wine valuation. Exceptionally, Georgantzis and Navarro (2010) report a negative effect of risk aversion on a consumer's valuation of a wine whose quality is unknown at the moment of valuation. According to this result, risk preferences elicited in the laboratory are externally valid and useful to predict how wine quality uncertainty will affect the valuation of a wine, depending on risk attitudes elicited in the monetary domain. This positive result concerning the external validity of risk elicitation measures is confirmed and extended here in a domain in which uncertainty is particularly present and relevant for consumer choice, namely, in the market for aged wines. Therefore, our study contributes to a long ongoing debate (see for example, Weber et al. 2002, Vieider et al. 2015, and Attanasi et al. 2018, Levy-Garboua et al. 2012) concerning the validity of risk preferences elicited through one instrument in one particular domain for preferences revealed in other, more or less distant domains.

In this paper, we are interested in the risk attitude of different types of consumers when buying aged wines. The link between a person's WTP for a vintage wine and her attitude towards uncertainty is rather straightforward. Consider a mean-variance model of risk-taking. The person wants to pay no more than the market valuation of the wine. Let us hypothesize that when the wine becomes older a variance is added to the value of the wine, with the "good" outcome of a well aging wine growing over time and the bad outcome being rather stable and bounded from below by the (dis)utility from opening a bottle of "vinegar". In this case a more risk averse person will be more affected by this variance and will be willing to pay less, while a risk loving person will be more attracted by the possibility of an excellent aged wine.

This laboratory experiment has been run with 65 participants with different profiles. During this experiment, participants had the opportunity to declare their willingness to pay for 20 bottles of aged wine by spending the money they were allocated at the beginning of the experiment. In another phase of the experiment, the subjects also completed a paid risk aversion test, and finally completed a questionnaire to collect some personal information that we considered relevant to refine our statistical analysis. In particular, the results of our study show that greater appetite for monetary risk is correlated with a significantly higher 
willingness to pay for over-aged wines. Also, self-assessed wine knowledge as well the WSET level of the subject is associated with a significant increase in willingness to pay.

The remainder of the article is organized as follows. In section 2 we present the experiment procedure as well as the experimental material we used to record the data. Section 3 provides a description of the data and variable. The results are presented and discussed in section 4. Section 5 concludes.

\section{Experimental procedures}

The experimental sessions took place at the School of Wine \& Spirits Business in Dijon between September 2017 and December 2018. In total, four experimental sessions were organized with 65 subjects with different profiles: students in Wine Business from the School of Wine \& Spirits Business, management students from the Burgundy School of Business and professionals from various fields attending to a visit of the school. Table 1 gives an overview of the number of sessions and subjects of each type.

\begin{tabular}{lcc}
\hline \multicolumn{1}{c}{ Type of subjects } & Total number of subjects & Number of sessions \\
\hline & & \\
Wine students & 30 & 2 \\
Management Students & 20 & 1 \\
Professionals & 15 & 1
\end{tabular}

The subjects received an invitation to the experiment by email. The four experimental session consisted of 25 subjects each and lasted approximately one hour. All subjects received a cash payment at the end of the experiment and/or a bottle of wine based on the decisions made during the experiment. 
The experiment was divided into three distinct and independent stages. In the first stage, subjects were asked to make four consecutive monetary decisions by picking their favorite lottery from 10 lotteries in each of the four separate tables presented in figure 1 . The objective of this first step is to measure the participants' monetary risk appetite in different situations, with varying amounts of money at stake. When a subject is risk neutral, he or she should choose the lottery with the highest expected gain, i.e. the most right-hand lottery in each of the tables. The higher the risk aversion of a subject, the more the subject's lottery choice will move to the left in order to have a greater chance of securing a gain. At the end of the experiment, one out of the four panels is randomly drawn with a dice in front of the participants. For that that panel, we roll a 10-sided dice to determine the winning choices (10 wins it all). This method of risk elicitation was introduced by Sabater-Grande and Georgantzis (2002), allowing a more systematic identification of the effect of stakes than that originally used by Holt and Laury (2002).

\begin{tabular}{|c|c|c|c|c|c|c|c|c|c|c|}
\hline Prob. of Winning & $100 \%$ & $90 \%$ & $80 \%$ & $70 \%$ & $60 \%$ & $50 \%$ & $40 \%$ & $30 \%$ & $20 \%$ & $10 \%$ \\
\hline Euros & 1 & 1.12 & 1.27 & 1.47 & 1.73 & 2.10 & 2.65 & 3.56 & 5.40 & 10.90 \\
\hline \multicolumn{11}{|l|}{ I prefer } \\
\hline \multicolumn{11}{|l|}{ PANEL 2} \\
\hline Prob. of Winning & $100 \%$ & $90 \%$ & $80 \%$ & $70 \%$ & $60 \%$ & $50 \%$ & $40 \%$ & $30 \%$ & $20 \%$ & $10 \%$ \\
\hline Euros & 1 & 1.20 & 1.50 & 1.90 & 2.30 & 3 & 4 & 5.70 & 9 & 19 \\
\hline I prefer & & & & & & & & & & \\
\hline \multicolumn{11}{|l|}{ PANEL 3} \\
\hline Prob. of Winning & $100 \%$ & $90 \%$ & $80 \%$ & $70 \%$ & $60 \%$ & $50 \%$ & $40 \%$ & $30 \%$ & $20 \%$ & $10 \%$ \\
\hline Euros & 1 & 1.66 & 2.50 & 3.57 & 5 & 7 & 10 & 15 & 25 & 55 \\
\hline I prefer & & & & & & & & & & \\
\hline \multicolumn{11}{|l|}{ PANEL 4} \\
\hline Prob. of Winning & $100 \%$ & $90 \%$ & $80 \%$ & $70 \%$ & $60 \%$ & $50 \%$ & $40 \%$ & $30 \%$ & $20 \%$ & $10 \%$ \\
\hline Euros & 1 & 2.20 & 3.80 & 5.70 & 8.30 & 12 & 17.50 & 26.70 & 45 & 100 \\
\hline I prefer & & & & & & & & & & \\
\hline
\end{tabular}

Figure 1: Risk aversion test

In the second phase of the experiment, all subjects start with an endowment of 18 euros allowing them to buy the different real bottles of wine presented to them during the experiment. If the subjects do not spend these 18 euros during the experiment, then the 18 euros are given to them in cash at the end of the experiment. Subjects are aware of this information before starting the experiment. In this step, we presented 20 bottles of aged 
wines to each participant. Participants have the opportunity to inspect the bottles one by one and are asked to write down in individual tables (one table per bottle) the price they are willing to pay for each of these bottles between 0 and 18 euros, in increments of 2 euros. Before declaring their willingness to pay for any of the wines, subjects are told that "the wines had aged under uncontrolled conditions and could therefore have turned sour, or still be as good as they were". In each session participants are assigned to a group of 3 or 4 participants that is not revealed before the end of the experiment. After each subject has announced how much she is willing to pay for all of the bottles, the groups are revealed and each group of 3 or 4 participants is assigned to a randomly selected bottle. The highest bid within the group for the bottle that has been randomly drawn wins the bottle and pays the announced price with her endowment. Participants in a group whose bid is not the highest keep their 18 euros in cash at the end of the experiment. That elicitation method allows participant to have their full endowment available for each bottle. Because participant do not know which bottle is going to be randomly drawn for their group, their best choice is to announce their actual willingness to pay for each bottle. Of course, this point was clearly explained to the participants before the experiment started so that no one believes she has to split her 18 euros among the 20 different bottles. Figure 1 shows the type of tables subjects had to fill for each bottle.

\begin{tabular}{|c|c|c|}
\hline & \multicolumn{2}{|c|}{ Would you buy the bottle? } \\
\hline $\mathbf{2} \boldsymbol{}$ & Yes & No \\
\hline $\mathbf{4}$ & Yes & No \\
\hline $\mathbf{6 \epsilon}$ & Yes & No \\
\hline $\mathbf{8} \epsilon$ & Yes & No \\
\hline $10 €$ & Yes & No \\
\hline $12 \epsilon$ & Yes & No \\
\hline $14 \epsilon$ & Yes & No \\
\hline $16 \epsilon$ & Yes & No \\
\hline $18 €$ & Yes & No \\
\hline $20 €$ & Yes & \\
\hline
\end{tabular}

Figure 2: Decision tables

Finally, in a third step, we asked subjects to complete a questionnaire including personal questions about their age, sex, nationality, knowledge of wine (WSET level and 9 selfassessment questions). More information about the questionnaire itself as well as a summary of descriptive statistics of these variables are presented in the next section. 


\section{Variables and data analysis}

During the four sessions, we collected observations about the subjects' risk aversion, willingness to pay for bottles of older wines aged in sub-optimal conditions, self-assessed knowledge about wine, WSET level, age, gender, and knowledge of the wine the subject is currently rating. ${ }^{6}$ Table 2 gives an overview of the descriptive statistics. More information about the self-reported knowledge in wines variable is available in appendix.

\begin{tabular}{|c|c|c|c|c|c|}
\hline Variable & $\begin{array}{c}\text { Description of the } \\
\text { variable }\end{array}$ & Average value & $\begin{array}{l}\text { Standard } \\
\text { deviation }\end{array}$ & Min & Max \\
\hline Bid & $\begin{array}{l}\text { Bid of a subject for } \\
\text { a wine expressed in } \\
\text { euros }\end{array}$ & 5.30 & 3.90 & 0 & 18 \\
\hline Risk Aversion 1 & $\begin{array}{lr}\text { Risk aversion } \\
\text { measured from } \\
\text { panel } 1 \text { from } 1 \text { to } 10\end{array}$ & 3.94 & 3.01 & 1 & 10 \\
\hline Risk Aversion 2 & $\begin{array}{lr}\text { Risk aversion } \\
\text { measured rom } \\
\text { panel } 2 \text { from } 1 \text { to } 10\end{array}$ & 3.71 & 2.47 & 1 & 10 \\
\hline Risk Aversion 3 & $\begin{array}{lr}\text { Risk aversion } \\
\text { measured rrom } \\
\text { panel } 3 \text { from } 1 \text { to } 10\end{array}$ & 3.81 & 1.96 & 1 & 8 \\
\hline Risk Aversion 4 & $\begin{array}{lr}\text { Risk aversion } \\
\text { measured rrom } \\
\text { panel } 3 \text { from } 1 \text { to } 10\end{array}$ & 3.24 & 1.92 & 1 & 7 \\
\hline Average risk average & $\begin{array}{l}\text { Average of four risk } \\
\text { aversion measures }\end{array}$ & 3.68 & 1.71 & 1 & 7.25 \\
\hline WSET & $\begin{array}{l}\text { WSET level of the } \\
\text { subject from } 0 \text { to } 5\end{array}$ & 0.61 & 1.11 & 0 & 3 \\
\hline Knowledge & $\begin{array}{l}\text { Self-reported } \\
\text { knowledge of wines } \\
\text { from } 1 \text { to } 7\end{array}$ & 3.95 & 1.33 & 2.40 & 6.80 \\
\hline Knowthiswine & $\begin{array}{l}\text { Dummy variable } \\
\text { equal to } 1 \text { if the } \\
\text { subject knows the } \\
\text { wine he is } \\
\text { evaluating }\end{array}$ & 0.42 & 0.52 & 0 & 1 \\
\hline
\end{tabular}

${ }^{6}$ For each wine subject had to answer if they know this wine. We control for the fact that subject know the wine with a dummy variable in the statistical analysis. 


\begin{tabular}{llllll}
\hline Gender & $\begin{array}{l}\text { Dummy variable } \\
\text { equal to } 1 \text { if the } \\
\text { subject is a woman }\end{array}$ & 0.62 & 0.47 & 0 & 1 \\
Age & $\begin{array}{l}\text { Age of the subject } \\
\text { Color }\end{array}$ & 25.7 & 6.27 & 18 & 1 \\
& $\begin{array}{l}\text { Dummy variable } \\
\text { equal to } 1 \text { if the } \\
\text { wine is red }\end{array}$ & 0.60 & 0.49 & 0 & 2012 \\
Year & $\begin{array}{l}\text { Year of production } \\
\text { of the wine }\end{array}$ & 2009 & 2.11 & 2004 & 14 \\
Alcoholcontent & $\begin{array}{l}\text { Alcohol content of } \\
\text { the wine }\end{array}$ & 13.18 & 0.46 & 12.5 &
\end{tabular}

Table 2: descriptive statistics

Given the high number of censored observations (Willingness to pay $=0$ ) and the sequential nature of the declaration of willingness to pay for each bottle, estimates are made with a tobit panel model. Results are shown in table 3. 


\begin{tabular}{|c|c|c|c|c|c|}
\hline & Model 1 & Model 2 & Model 3 & Model 4 & Model 5 \\
\hline \multirow[t]{2}{*}{ Average risk } & $-0.536^{* * *}$ & & & & \\
\hline & $(-6.40)$ & & & & \\
\hline \multirow[t]{2}{*}{ Risk panel 1} & & $-0.226 * * *$ & & & \\
\hline & & $(-4.48)$ & & & \\
\hline \multirow[t]{2}{*}{ Risk panel 2} & & & $-0.384 * * *$ & & \\
\hline & & & $(-6.65)$ & & \\
\hline \multirow[t]{2}{*}{ Risk panel 3} & & & & $-0.374 * * *$ & \\
\hline & & & & $(-5.01)$ & \\
\hline \multirow[t]{2}{*}{ Risk panel 4} & & & & & $-0.200 * *$ \\
\hline & & & & & $(-2.45)$ \\
\hline \multirow[t]{2}{*}{ Wine student } & $1.463^{* * *}$ & $1.138^{* * *}$ & $1.720^{* * *}$ & $1.562^{* * *}$ & $1.643^{* * *}$ \\
\hline & (3.65) & $(2.75)$ & $(4.27)$ & (3.86) & (3.99) \\
\hline \multirow[t]{2}{*}{ Know this wine } & $1.478^{* * *}$ & $1.458^{* * *}$ & $1.393^{* * *}$ & $1.425^{* * *}$ & $1.377^{* * *}$ \\
\hline & $(4.82)$ & $(4.71)$ & $(4.55)$ & $(4.62)$ & $(4.42)$ \\
\hline \multirow[t]{2}{*}{ Female } & $-0.623^{* *}$ & $-0.637^{* *}$ & $-0.742^{* *}$ & $-0.642 * *$ & -0.764 \\
\hline & $(-2.07)$ & $(-2.09)$ & $(-2.47)$ & $(-2.11)$ & $(-2.50)$ \\
\hline \multirow[t]{2}{*}{ Age of subject } & $-0.109 * * *$ & $-0.0904 * * *$ & $-0.114 * * *$ & $-0.106 * * *$ & $-0.0959 * * *$ \\
\hline & $(-4.33)$ & $(-3.59)$ & $(-4.53)$ & $(-4.17)$ & $(-3.76)$ \\
\hline \multirow[t]{2}{*}{ Knowledge } & $-0.621 * * *$ & $-0.620 * * *$ & $-0.451 * * *$ & $-0.658 * * *$ & $-0.546 * * *$ \\
\hline & $(-3.90)$ & $(-3.84)$ & $(-2.84)$ & $(-4.05)$ & $(-3.38)$ \\
\hline \multirow[t]{2}{*}{ WSET } & $-0.882^{* * *}$ & $-0.683 * * *$ & $-0.958 * * *$ & $-0.871 * * *$ & $-1.062 * * *$ \\
\hline & $(-4.34)$ & $(-3.24)$ & $(-4.70)$ & $(-4.25)$ & $(-4.91)$ \\
\hline \multirow[t]{2}{*}{ Red wine } & 0.0853 & 0.101 & 0.102 & 0.0827 & 0.131 \\
\hline & $(0.29)$ & $(0.34)$ & $(0.34)$ & $(0.28)$ & $(0.43)$ \\
\hline \multirow[t]{2}{*}{ Year of production } & -0.0111 & -0.0118 & -0.00719 & -0.00750 & -0.00881 \\
\hline & $(-0.16)$ & $(-0.16)$ & $(-0.10)$ & $(-0.10)$ & $(-0.12)$ \\
\hline \multirow[t]{2}{*}{ Alcohol content } & -0.0461 & -0.0447 & -0.0400 & -0.0421 & -0.0339 \\
\hline & $(-0.92)$ & $(-0.89)$ & $(-0.80)$ & $(-0.84)$ & $(-0.67)$ \\
\hline \multirow[t]{2}{*}{ French wine } & 0.200 & 0.206 & 0.208 & 0.204 & 0.222 \\
\hline & $(0.46)$ & $(0.47)$ & $(0.48)$ & $(0.47)$ & $(0.50)$ \\
\hline \multirow[t]{2}{*}{ Cons } & 34.52 & 34.32 & 25.59 & 26.78 & 27.99 \\
\hline & $(0.24)$ & $(0.24)$ & $(0.18)$ & $(0.19)$ & $(0.19)$ \\
\hline $\begin{array}{l}\text { Number of } \\
\text { observations }\end{array}$ & 1016 & 1016 & 1016 & 1016 & 1016 \\
\hline
\end{tabular}

Tstatistics in parentheses, ${ }^{*} p<0.1,{ }^{* *} p<0.05, * * * p<0.01$

Table 3: Estimates from the tobit panel model

The results we obtain highlight several interesting relationships. Subjects report a significantly higher willingness to pay when their appetite for monetary risk is higher. This result is valid 
for any of the four risk aversion variables, as well as the average risk aversion. The coefficient associated with risk aversion estimation from panel 4 , which is the panel with the highest stakes, shows a weaker significance. This result is not so surprising since the highest reward (100 euros) of this panel is so appealing that non trivial number of subjects picked this option even though they picked much safer choices in previous panels. Interestingly, while old winerelated uncertainty and monetary risk are certainly two different domains involving risky choices, we confirm the external validity of in-lab risk elicitation tools like the lottery panel test adopted here.

Subjects' knowledge about wine is also an important variable of their willingness to pay for aged wines. Subjects with higher self-reported knowledge and higher WSET level show, on average, a significantly lower willingness to pay for aged wines. This result might highlight the fact that people with lower knowledge overestimate the probability that an over-aged wine that aged under uncontrolled conditions could still be worth consuming. It is very likely that more informed subjects about wines are more likely to know this information.

Finally, results show that wines' characteristics we control for (year, color, degree of alcohol and French wine) do not significantly interfere with subjects' willingness to pay. This result, as surprising as it might be, does not mean that wines' characteristics were totally irrelevant to determine subjects' willingness to pay in this experiment. There are a lot of other wines' characteristics such as the grape variety, the wine producer, the region of origin, the style of the label that we were not able to control for in the econometric analysis due to the lack of replicates of each of these characteristics in our wines sample. 


\section{Conclusion}

While the regulatory environment of food and beverages production tends to harden over time, we still know very little about people's risk preferences towards this kind of products. In this study, we attempted to establish a statistical relationship between subjects' monetary risk aversion and risk preferences toward aged wines. For that purpose, we ran laboratory experiments with 65 subjects with different profiles and real money. Our results show in particular that a lower risk aversion for monetary choices is associated with a higher willingness to pay for risky wines. Also, we show that subjects' knowledge about wines in general leads to a significantly lower willingness to pay for aged wines. These results sheds new light on wine consumers' behaviour, especially on aged wines that attract an increasing number of consumers in auctions.

Despite interesting results, one important shortcoming should be mentioned. The wine characteristics we included in the statistical analysis were not enough to control for the attributes of the wines that significantly interfere with subjects' willingness to pay for aged wines. Even though we were aware of this before running the experiment, the pool of bottles we had access to for the experiment was not large enough to have a sufficient number of replicates of some characteristics (e.g, different wines by one winemaker in order to identify winemakers fixed effects). Also, there was no wine that had a special reputation for aging really well in the sample of bottle we used. Even though these discrepancies do not question the robustness of our results regarding our main focus which is the relationship between subjects' monetary risk aversion and their willingness to pay for aged wines, we believe the results could have been more refined and informative with a larger sample of bottles including replicates of some characteristics worth of interest. We nevertheless remain hopeful that our results will inspire future studies and open the path for further research on this this topic. 


\section{References}

Andersen, S., Harrison, G. W., Lau, M. I., \& Rutström, E. E. (2006). Elicitation using multiple price list formats. Experimental Economics, 9, 383-405.

Attanasi, G., Georgantzís, N., Rotondi, V., \& Vigani, D. (2018). Lottery- and survey-based risk attitudes linked through a multichoice elicitation task. Theory and Decision, 84, 341-372.

Charness, G., Gneezy, U., \& Imas, A. (2013). Experimental methods: eliciting risk preferences. Journal of Economic Behavior and Organization, 87, 43-51.

Cubitt, R. P., Navarro-Martinez, D., \& Starmer, C. (2015). On preference imprecision. Journal of Risk and Uncertainty, 50, 1-34.

García-Gallego, A., Georgantzís, N., \& Jaramillo-Gutiérrez, A. (2012). Gender differences in ultimatum games: Despite rather than due to risk attitudes. Journal of Economic Behavior \& Organization, 83(1), 42-49.

Georgantzís, N., \& Navarro-Martínez, D. (2010). Understanding the WTA-WTP gap: attitudes, feelings, uncertainty and personality. Journal of Economic Psychology, 31, 895-907.

Holt, C. A., \& Laury, S. K. (2002). Risk aversion and incentive effects. American Economic Review, 92, 1644-1655.

Jovanovic, B. (2007). Bubbles in prices of exhaustible resources (No. w13320). National Bureau of Economic Research.

Lévy-Garboua, L., Maafi, H., Masclet, D., \& Terracol, A. (2012). Risk aversion and framing effects. Experimental Economics, 15, 128-144.

Noparumpa, T., Kazaz, B., \& Webster, S. (2015). Wine futures and advance selling under quality uncertainty. Manufacturing \& service operations management, 17(3), 411-426.

Sabater-Grande,G., \& Georgantzis,N. (2002). Accounting for risk aversion in repeated prisoners' dilemma games: an experimental test. Journal of Economic Behavior and Organization, 48, 37-50.

Vieider, F. M., Lefebvre, M., Bouchouicha, R., Chmura, T., Hakimov, R., Krawczyk, M., et al. (2015). Common components of risk and uncertainty attitudes across contexts and domains: evidence from 30 countries. Journal of the European Economic Association, 13, 421-452.

Weber, E. U., Blais, A.-R., \& Betz, N. E. (2002). A domain-specific risk-attitude scale: measuring risk perceptions and risk behaviors. Journal of Behavioral Decision Making, 15, 263-290. 